\title{
Influence of Crystal Habit on the Dissolution of Simvastatin Single Crystals
}

\section{Polona Bukovec, ${ }^{1,3} *$ Anton Meden, ${ }^{2}$ Matej Smrkolj ${ }^{1}$ and Franc Vrečer ${ }^{1,3}$}

\author{
${ }^{1}$ KRKA d.d., Novo mesto, Šmarješka cesta 6, 8501 Novo mesto, Slovenia \\ ${ }^{2}$ University of Ljubljana, Faculty of Chemistry and Chemical Technology, Večna pot 113, 1000 Ljubljana, Slovenia \\ ${ }^{3}$ University of Ljubljana, Faculty of Pharmacy, Aškerčeva 7, 1000 Ljubljana, Slovenia \\ * Corresponding author: E-mail: polona.bukovec@krka.biz \\ Tel.: +38673317547
}

Received: 27-07-2015

\begin{abstract}
In order to achieve better in-vivo performance of the final dosage form comprising a poorly soluble drug the physicochemical properties of the active pharmaceutical ingredient can be altered not only by changing the solid state form but also through the conversion of their crystal habits. To elucidate this approach in the case of simvastatin, the dissolution behaviour of large crystals with the same internal structure but expressing different crystal habits was studied using atomic force microscope. The obtained differences in the dissolution were explained through the determination of crystal morphology, its orientation and assignation of the molecular functional groups that were emerging on the surface of the dissolving crystal face. The dissolution rates of the particular crystal faces measured in situ by atomic force microscopy were found to be distinctly higher than others. The dissolution rate of single crystals differed as a consequence of higher incidence of more polar crystal faces in case of rod shaped crystals isolated from more hydrophilic solvent mixture which we have established through a thorough research of the single crystal morphology, orientation and the assignation of specific functional groups for each of evolved crystal faces.
\end{abstract}

Keywords: Simvastatin, crystal habit, single crystal orientation, atomic force microscope, dissolution rate

\section{Introduction}

When developing an oral solid dosage form with poorly water soluble active pharmaceutical ingredients (APIs) it is of utmost importance to thoroughly evaluate and understand the physicochemical nature of the chosen API, which has to be carefully selected and specified in order to ensure repeatable income material with desired functional properties for the final dosage form.

Most marketed pharmaceuticals contain APIs in the form of molecular crystals. ${ }^{1}$ The arrangement of the molecules in such a crystal defines its physicochemical properties which in consequence determine the performance of the API in the final dosage form in terms of dissolution rate, physical and chemical stability and processibility by affecting its shape and mechanical properties. ${ }^{2}$

In order to enable reproducible characteristics of the final dosage form, the internal structure and particle size, sometimes also specific surface area of the API, are usual- ly defined in a relative narrow range. This, however, is not always sufficient. Additional characteristics of the API have to be defined to achieve the specified in-vitro characteristics of the final dosage form in order to produce a highquality, safe and efficient drug product, such as crystal habit, hydrophillicity of the bulk sample or other properties which reflect a certain position of the exposed functional groups on the surface and the incidence of those.

Crystal habit is defined during the crystallization process. ${ }^{3}$ When considering structures with the same internal structure, possessing different crystal habit, the mechanical and chemical properties of such crystals can vary significantly.

For the present study, simvastatin was selected as a model poorly soluble API with aqueous solubility of 30 $\mu \mathrm{g} / \mathrm{mL}^{4}{ }^{4}$ Simvastatin is a derivative of lovastatin and is a potent competitive inhibitor of 3-hydroxy-3-methylglutaryl coenzyme A reductase, a rate-limiting enzyme in cholesterol biosynthesis. It may also interfere with steroid 
hormone production. ${ }^{5}$ Simvastatin is a BCS Class II drug. ${ }^{6}$ Its solubility is therefore a crucial rate limiting factor to achieve the desired level in systemic circulation for pharmacological response. ${ }^{5}$

Although polymorphism is a very common phenomenon among active pharmaceutical substances, ${ }^{7}$ detailed searches in the literature and the Cambridge Structural Database $^{8}$ revealed only one known stable crystal structure of simvastatin at room temperature, ${ }^{9}$ first reported in 2002 by Čejka et. al. ${ }^{10}$ In some cases, a lack of polymorphism in APIs may be an advantage, since no phase transformations, which could affect the performance of the drug, can occur during manufacturing, storage or administration (Brittain, 2002, ${ }^{11}$ Zhang et al., 2004 ${ }^{12}$ ). However, there is less space for the improvement of the aqueous solubility of simvastatin by physical modification of the API itself, e.g. selecting a more/less soluble polymorphic form in connection to the particle size and specific surface area. The presence of different simvastatin crystal habits may provide a possibility to alter the properties of simvastatin in order to enhance its dissolution rate.

Knowledge about the dissolution rate and also the dissolution mechanism of the different crystal faces is becoming progressively interesting and valuable method for the characterisation of poorly soluble active pharmaceutical ingredients. ${ }^{7,13}$ In our study the use of atomic force microscopy for this purpose is presented.

The influence of different crystal habit of active pharmaceutical ingredient on the physico-chemical and biopharmaceutical properties of the final dosage form has been studied by various research groups. Crystal habit can significantly influence for instance the disintegration capability ${ }^{14}$ of tablets, their crushing strength ${ }^{15}$ compactibility ${ }^{16}$ and the dissolution behaviour. ${ }^{14,16}$

It is known ${ }^{13,17,18}$ that different crystal planes possess different surface energy properties and can therefore exhibit different dissolution kinetics which are demonstrated among others in the work of Tenho et.al. ${ }^{17}$ who used this technique to study the dissolution behaviour of acetylsalicylic acid and tolbutamide and Prasad et al. ${ }^{13}$ on paracetamol single crystals. These published studies suggest that it is possible to modify the dissolution rate of the active pharmaceutical ingredients by altering only their crystal habits. The purpose of our research was to crystalize large crystals expressing different crystal habits, determine the dissolution rate of individual crystal faces and explain the observed differences in the dissolution behaviour of simvastatin crystals on the molecular level.

The difference in the dissolution rate of crystals possessing different crystal habits was usually studied on bulk samples and explained in connection to polymorphic transitions or different particle size and specific surface area.

The focus of the present study was to explain different dissolution kinetics of simvastatin crystals possessing different crystal habits at the molecular level. This was ac- hieved through the assignation of specific functional groups for each evolved crystal face and the incidence of those. Present work additionally elucidated in more detail the same effect we have observed during our previous research performed on small simvastatin crystals expressing the same difference in their crystal habit.

\section{Materials and Methods}

\section{1. Materials}

We have performed several sets of experiments where we have used different crystallization approaches and different solvents and their mixtures in order to isolate simvastatin crystals expressing different crystal habit. During first sets of experiments small crystals were isolated. By altering the crystallization conditions we were then able to crystallize large simvastatin crystals expressing the same difference in their crystal habit as the small crystals had.

The solvents used in our experiments differed in their polarity. More polar solvent mixture was composed of acetone (Merck, Germany) and water and for the less polar solvent mixture ethanol (Riedel de Haën, Germany) and $n$-heptane (Merck, Germany) were selected. All the solvents were analytical grade.

The water used for crystallization and surface characterization was organic-free, distilled water.

Untreated simvastatine was donated by Krka, d. d., Novo mesto, Slovenia.

\section{2. Methods}

\section{2. 1. Crystalizaton of Large Single Crystals Expressing Different Habits}

Large single crystals of simvastatin having the same crystal structure but different crystal habits were prepared by recrystallization of untreated simvastatin from solvent mixtures exhibiting different polarity. A mixture of acetone and water and a mixture of ethanol and $n$-heptane were selected. By using these solvent mixtures we were able to prepare large and also small simvastatin crystals with the same crystal habit by only altering some of the crystallization process conditions, mainly the isolation time.

\section{2. 1. Crystallization from Hydrophilic Solvent Mixture (acetone/water)}

Untreated simvastatin $(10 \mathrm{~g})$ was dissolved in $30 \mathrm{~mL}$ of acetone at room temperature. To the clear solution $30 \mathrm{~mL}$ of water (antisolvent) was added slowly during $30 \mathrm{~min}$ mixing at room temperature. The reaction mixture was stirred with an overhead stirrer at 250 RPM. After $17 \mathrm{ml}$ of the antisolvent was added to the reaction mixture, a two-phase system was formed. The solute separated from the solution in the form of droplets resulting in emulsion of the oily solute in the solvent mixture. 
After the entire amount of antisolvent was added, the formation of crystals from the oily phase was observed resulted in thick suspension. The suspension was allowed to evaporate slowly at room temperature for 1 week in order to obtain large crystals which were additionally dried in a desiccator for $24 \mathrm{~h}$ and stored in appropriate airtight container for further analytical evaluation.

\section{2. 1. 2. Crystallization from Hydrophobic Solvent Mixture (ethanol/n-heptane)}

Simvastatin $(5 \mathrm{~g})$ was dissolved in $13 \mathrm{~mL}$ of absolute ethanol at $38{ }^{\circ} \mathrm{C}$. A clear solution was added to cooled (15 $\left.{ }^{\circ} \mathrm{C}\right)$ heptane $(65 \mathrm{~mL})$ in the reactor equipped with an overhead stirrer in $10 \mathrm{~min}$. When a droplet contacted the antisolvent, the nucleation of particles was observed followed by their dissolution. When the entire amount of the simvastatin solution was added, some particles remained undissolved. Hazy solution was heated to $37^{\circ} \mathrm{C}$ and covered with a membrane (parafilm). Solvent was allowed to slowly diffuse trough a membrane for 1 month in order to obtain large crystals which were afterwards isolated and dried in a desiccator for $24 \mathrm{~h}$ at room temperature and stored in appropriate airtight container for further analytical evaluation.

\section{2. 2. Characterization of Starting Material and Isolated Crystals}

Powder X-ray diffraction patterns of simvastatin crystals were obtained using the X-ray diffractometer Panalytical (X'Pert PRO MPD, Netherlands), at $45 \mathrm{kV} 40$ $\mathrm{mA}$, over the range of $3-50^{\circ} 2 \theta$, using $\mathrm{CuK} \alpha$ radiation wavelength $1,541 \AA$.

Single-crystal X-ray diffraction was used to determine the indices of the crystal faces. This task was performed on a Nonius Kappa CCD diffractometer using MoK $\alpha$ radiation and the NoniusCollect software. Large single crystals were glued to the holder and positioned onto the goniometer. Indices of the crystal faces were determined, using the "Orient Measure Crystal" within the software package.

After the crystals were characterized as such to know the indices of crystal faces, we were then able to monitor each individual crystal face in order to obtain information about its properties with regard to their dimensions, topography, mechanical properties and the dissolution kinetics.

Evaluation of crystal habit was performed using a scanning electron microscope (ULTRA plus, Carl Zeiss, GER). Crystals were characterised before and after the exposure to the dissolution medium phosphate buffer with $\mathrm{p}$ $\mathrm{H}$ of 6.8 with $0.5 \%$ sodium lauryl sulphate (SDS).

The atomic force microscope Innova microscope, Veeco, USA with CP-II MicroCell, was used for the determination of mechanical properties and the in situ dissolution study. A 3D AFM image analysis was performed by NanoScope Analysis software.
For the dissolution study we carefully placed the crystal in the liquid chamber of the AFM microscope, secured the crystal with a double-sided adhesive tape and carefully added the dissolution media without the formation of air bubbles using a syringe. The dissolution was measured in a static environment since simvastatin has a very low solubility in aqueous media; in this way the differences were more pronounced and the measurements were stable. The AFM probe was then adjusted in a way that one edge of the crystal face to be examined was perpendicular.

As the crystal dissolved, the regression of the crystal face was measured as a function of time. Dissolution measurements were stopped when the formed voids were too big to measure using the AFM probe. Measurements were conducted at room temperature on all major accessible crystal faces on three individual crystals for each habit. The scanning range was $95 \times 95 \mu \mathrm{m}$.

Mechanical properties were determined through the measurement of Young's Modulus according to the Hertz model with SPIP 6.0.13 software. AFM probe was used as a picoindenter (force spectroscopy mode). This approach models the interaction between the tip and sample as two springs in a series. The small indentation depths and low loads create an elastic interaction between the tip and sample. The elasticity of the material is then calculated from the obtained force curves (Hoffman).

\section{Results and Discussion}

\section{1. Crystal Structure}

In order to perfom indexing of the developed crystal faces by conventional single-crystal X-ray diffractometry (SCXRD), which requires crystals of a suitable size and quality, single crystals of sufficient quality were grown. In general, the minimum dimension along each axis of the crystal should exceed 50 microns, unless a heavy atom (atomic number $>17$ ) is present in constituent molecules ${ }^{2}$. Simvastatin crystals selected for the X-ray study were about $5 \mathrm{~mm}$ long and about 200-400 $\mu \mathrm{m}$ wide.

To obtain information on physicochemical characteristics of the prepared crystals, X-ray powder diffraction measurements were conducted. As it is known from the work of Hušak et.al. ${ }^{9}$, simvastatin can be found in three crystal modifications, with only Form I being stable at temperatures higher than $272 \mathrm{~K}$. Form II is present within the temperature range between 272 and $232 \mathrm{~K}$, and Form III at temperatures below $232 \mathrm{~K}$. The lattice parameters between those three modifications almost do not change and even the transformation to the lower symmetry (monoclinic space group P21) for form III does not result in significantly different crystal lattice. According to Čejka et. $\mathrm{al}^{10}$ who were the first to determine the crystal structure of simvastatin, simvastatin crystallizes in an orthorhombic structure with the space 


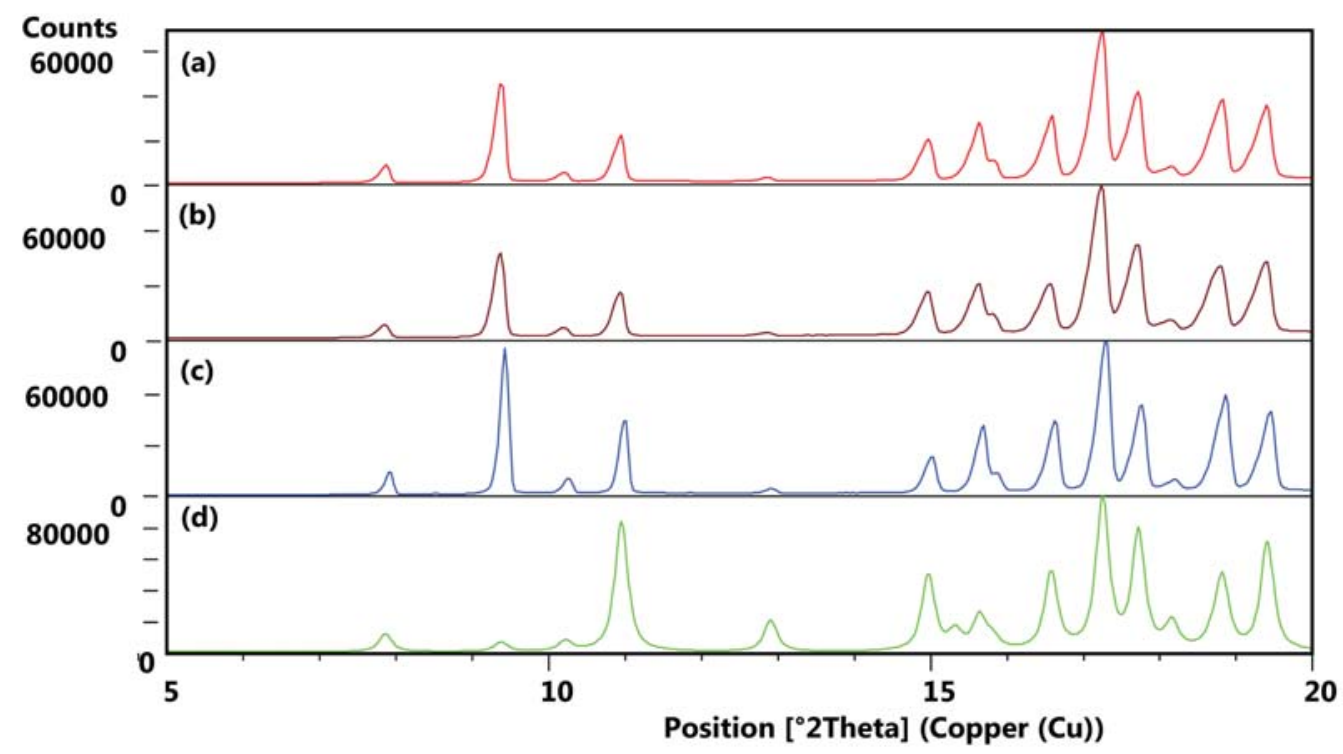

Figure 1: X-ray powder diffraction patterns of milled crystals: a) untreated material, b) crystals isolated from a hydrophilic solvent mixture c) crystals isolated from a hydrophobic solvent mixture, d) calculated mono-crystal structure data ${ }^{10}$

group $\mathrm{P} 212121, \mathrm{Z}=4$ and unite cell parameters $\mathrm{a}=$ $6.128 \AA, b=16.296 \AA, c=22.466 \AA$.

Our powder diffraction data collected on gently milled large crystals prove the consistency with the data published for simvastatin form I. As it can be seen from the recorded X-ray powder diffraction patterns (Fig.1), both recrystallized samples have the same crystal structure and the degree of crystallinity which is also comparable to the starting material, i.e. "untreated simvastatin".

\section{2. Crystal Habit}

The crystals, isolated from more hydrophilic solvent mixture are rod-shaped. Their longest dimension extends along the 100 crystallographic direction and the crystal faces at each end are normally broken, close to being per- pendicular to the longest dimension and were thus described as (100) and (-100). The projection of the rod along the longest dimension is more or less distorted hexagon with the same types of crystal faces being always developed: (011), (0-1-1) (0-11), (01-1), (001) and (00-1) (Fig. 2a). Crystal faces (001) and (00-1) are significantly smaller than the other four. Crystals isolated from the hydrophobic solvent mixture are thinner, more plate-like, with crystal faces (001) and (00-1) being the most expressed, whereas other four are less evolved (Fig. 2b); in extreme cases this pair of crystal faces becomes very dominant.

Typical microscopic images of the obtained crystals from each solvent mixture are shown in Fig. 3a and Fig. 3d.

SEM analysis revealed numerous circular irregularities (Fig. 3d) on the surface of the hydrophobic crystals, which were formed when the residual heptane evaporated

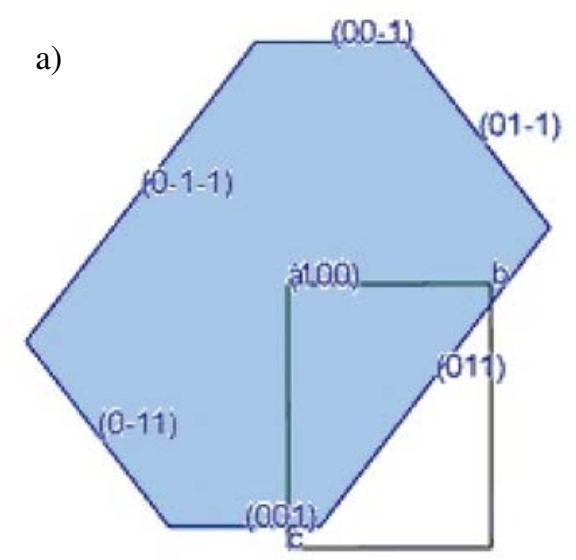

b)

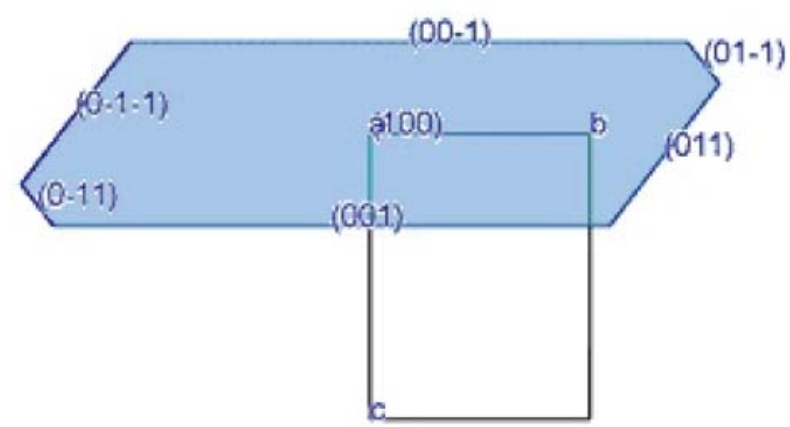

Figure 2: Crystal faces of crystals isolated from hydrophilic (a) and hydrophobic (b) solvent mixture. All crystals are projected along the a axis 


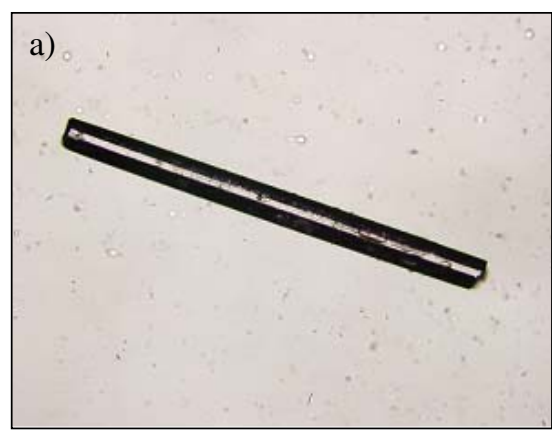

d)

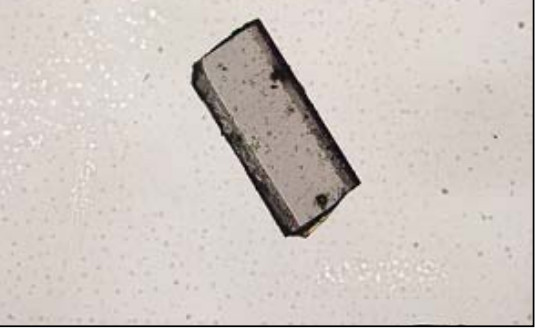

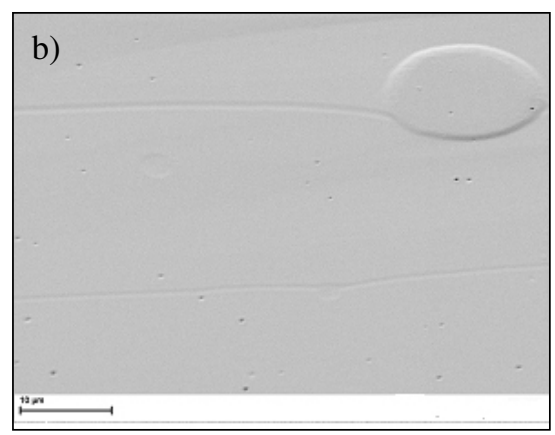

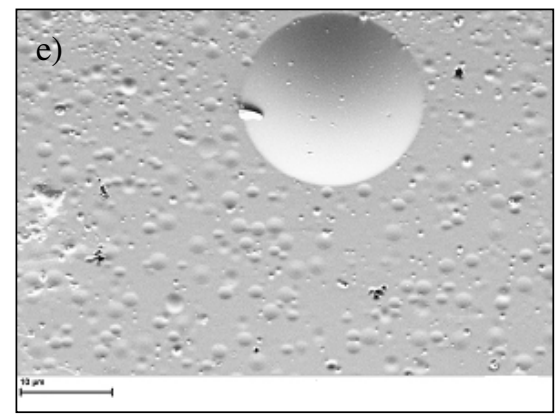

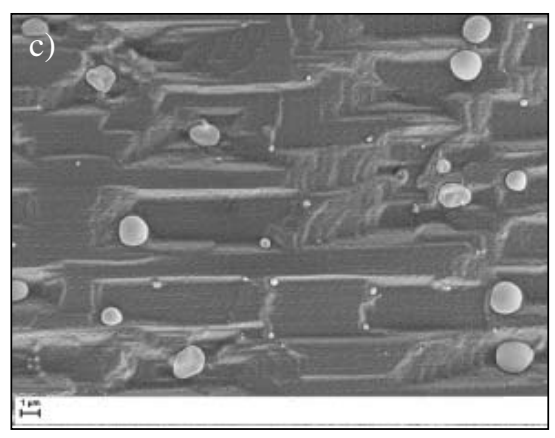

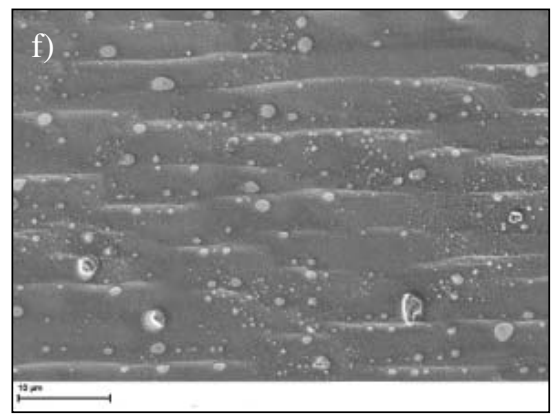

Figure 3: Microphotographs and SEM images obtained on rod-shaped crystals (a-c) and plate-like crystals (d-f) showing their shape (a and d) and close-up images which show the surface topography before $(\mathrm{b}, \mathrm{e})$ and after $(\mathrm{c}, \mathrm{f})$ the exposure to the dissolution medium at final time point $5 \mathrm{~h}$.

from the crystals during their growth. Crystals obtained from a hydrophilic solvent mixture exhibit a smooth surface (Fig. 3b).

\section{3. The Connection Between the Crystal Structure and Crystal Shape}

The key drivers which define the shape of the growing crystal are related to the crystal lattice energy of the molecular solids. However the lattice energy is not the only influencing factor. The crystallization kinetics is also important since it influences not only the size and morphology of the crystals, but also their structure. ${ }^{19}$

As proposed in the work of Berkowitch et.al. ${ }^{20}$ the difference in the crystal habit is attributed to the effect of solvent, namely the preferential adsorption of the solvent molecules on specific crystal faces. A delay in growth of some crystal faces is attributed to the prerequisite need of solvation layer removal prior to the deposition of the next growing layer. Since polar solvents preferentially interact with polar crystal faces, the most pronounced effect is anticipated for crystals exhibiting faces with significant differences in their polarity. The polarity of a crystal face is determined by the atoms or functional groups which are exposed normal to the face and are easily accessed by the solvent molecules.

In our case, the biggest difference between the samples isolated from the hydrophilic solvent mixture, in comparison to those from a more hydrophobic solvent mixture, was the relative growth along the c-axis in com- a)

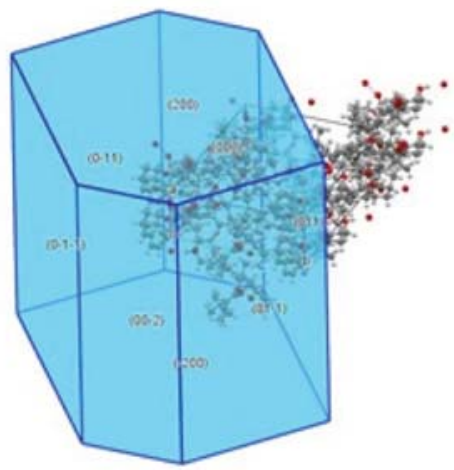

b)

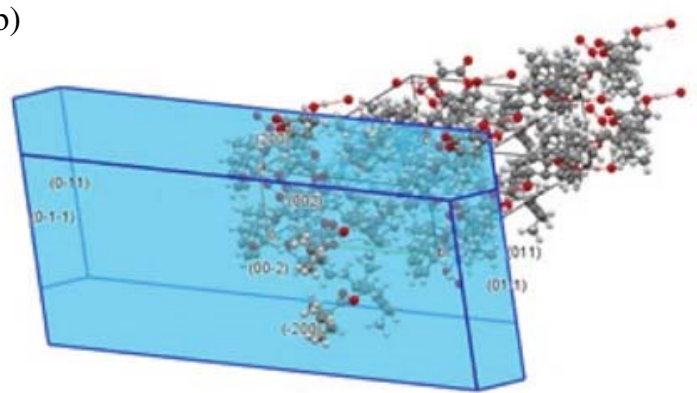

Figure 4: Packing arrangement of simvastatin in connection to the crystal habit (a) isolated from a hydrophilic solvent mixture and (b) isolated from a hydrophobic solvent mixture 


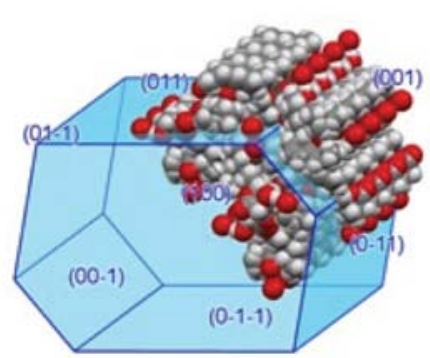

(001)

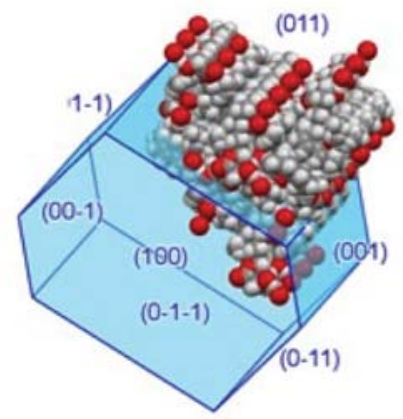

(011)

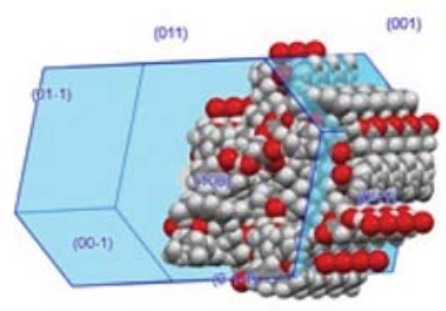

$(0-11)$

Figure 5: A schematic view of simvastatin molecules positioned on the individual faces

parison to the growth in the directions of the diagonals between $\mathrm{c}$ and $\mathrm{b}$ axes. Growth along the $\mathrm{c}$ axis was the fastest in the case of crystals grown from a hydrophilic solvent mixture, thus the formed crystals have less prominent (001) and (00-1) pair of crystal faces and more expressed (0-1-1), (011) and (0-11), (01-1) pairs of crystal faces.

In the crystal lattice simvastatin molecules are interconnected with hydrogen bonds which facilitate the formation of infinite chains along the $b$ axis (the hydroxyl group of the oxooxan cycle is connected to the carbonyl group of the 2,2-dimethylbutanoate). Molecular clusters form a zig-zag pattern, which is exposed on the (001) crystal face. This face thus consists of voids which can form H-bonds and convex hydrophobic areas where mainly hexahydronaphtalene rings and 2,2-dimethylbutanoil groups are present (Fig.5).

The crystal face (011) is of a more hydrophilic nature since simvastatin molecules are bound by $\mathrm{H}$-bonds in this direction. On this face mostly methyl-groups of the hexahydronaphtalen ring and oxooxane rings are present. The crystal face (0-11) is composed of hexahydronaphatlen rings and 2,2 dimethylbutanoil groups with the possibility of forming H-bonds.

The zig-zag pattern is also evident on the crystal face (100), with convex hexahydronaphtalene rings and voids where oxooxan rings are present which are able to form H-bonds.

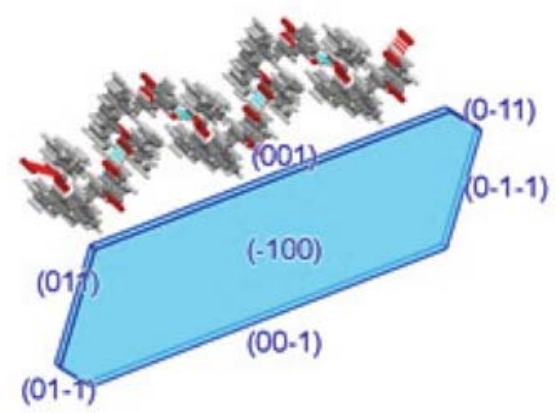

Figure 6: A zig-zag pattern of simvastatin molecules bound together with hydrogen bonds (blue)

\section{4. Mechanical Properties of Large Simvastatin Crystals}

Young's modulus also known as elastic or tensile modulus was determined for all crystal faces and compared between both types of samples. It measures the force needed to stretch the analysed material. A material whose Young's modulus is very high can be approximated as rigid. ${ }^{21}$

The results in Table 1 show mechanical properties of the grown crystals. The values obtained on the same crystal face did not differ between crystals expressing different morphology. In all cases the crystal face 001 is the most rigid one, whereas faces (011) and (01-1) are softer and of similar elasticity.

Table 1: The results of Young's modulus (E) obtained from the most prominent faces of simvastatin crystals given as the average value of all measured crystals

\begin{tabular}{lccc}
\hline & $(001)$ & $(01-1)$ & $(011)$ \\
E [GPa] & $\mathbf{3 . 1} \pm \mathbf{0 . 0 5}$ & $\mathbf{0 . 1 5} \pm \mathbf{0 . 0 3}$ & $\mathbf{0 . 1 7 \pm 0 , 0 8}$ \\
\hline
\end{tabular}

\section{5. The Dissolution Kinetic of Single Crystals}

Furthermore we wanted to correlate the properties of different exposed crystal faces to the different dissolution behaviour of crystals through explanation of their ability to exhibit hydrophilic interactions with the aqueous dissolution media as a consequence of exhibition of different molecular functional groups exposed at each crystal face. ${ }^{22}$

The use of AFM permits direct nano- to micro- meter scale in-situ observation of solid crystal-water reaction processes occurring on single crystal surfaces and dissolution processes are monitored through topographic changes of the crystal surface over time. ${ }^{23}$

The crystals selected for the dissolution experiment were approximately $0.5-1 \mathrm{~cm}$ long with well defined faces. Only one crystal face per crystal was studied in each expe- 
riment. The results thus represent the behaviour of a total of 6 separate crystals for each experiment. Since there were little differences between each crystal (less than 5\%), we believe the results are representative for the whole sample.

As demonstrated (Fig. 7-9) the dissolution kinetics of the crystal face (011) is much faster in comparison to (001). The crystal face with lower dissolution rate is more expressed in case of plate-like crystals. Satisfactory measurements of the crystal face (011) could be made only on rod-shaped crystals (Fig. 7) since this face was too small for accurate examination of the plate-like crystals.

We have observed that the voids which form when the molecules transit to the dissolution media are rectangular-shaped. It is evident from the estimated volume of the dissolving phase (volume of the formed void) that Large molecular clusters (approximately $10^{8}$ molecules per hour per individual void) rather than individual molecules dissolve through the observed time-points.

The dissolution behaviour of the (001) crystal face was analysed also on rod-shaped crystals. Both cases show lower dissolution rate of this crystal face in comparison to the crystal face (011); its character is therefore more hydrophobic.

The comparative dissolution profile of the (001) and (011) crystal faces is shown on Figure 9. During the dissolution study not only voids were forming but also the sur- face of the crystals was slowly dissolving so they were becoming thinner (shown on Fig. 7c-d). We have therefore plotted the results of the measured surface area of the formed void for each time point rather than the volume of the voids itself. The results represent an average value of the measured projected area (2D) of 10 individual voids for each time point.

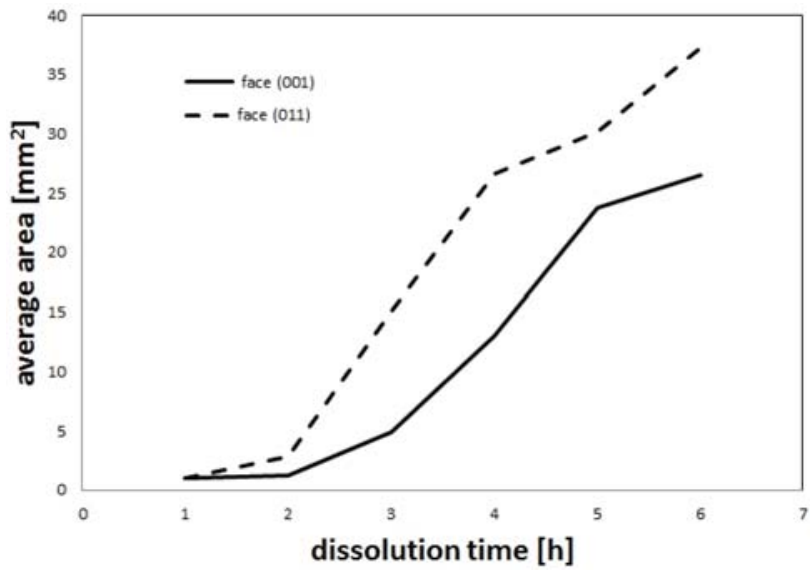

Figure 9: Area of the formed voids as a function of the dissolution time. Average of the measured projected area (2D) of 10 individual voids is plotted for each time-point

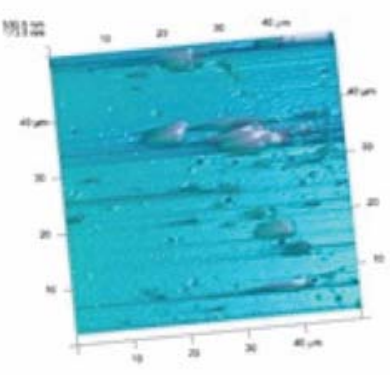

a)

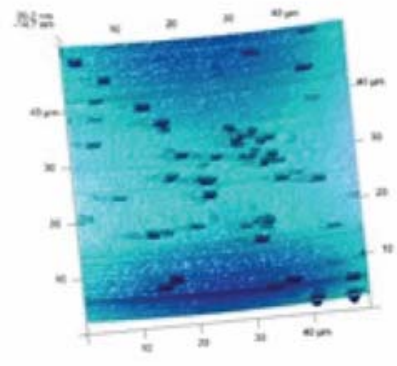

b)

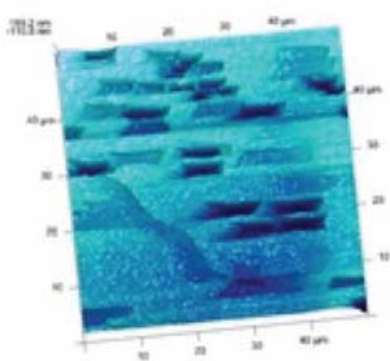

c)

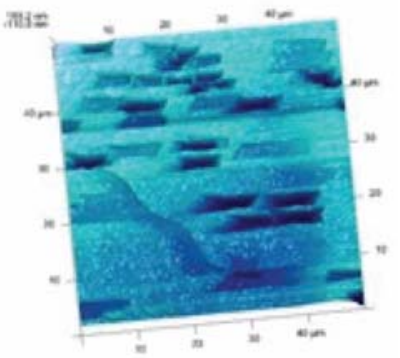

d)

Figure 7: Surface topography of the face 011 of the large crystals exposed to the dissolution media recorded at time points 0 (a), $1 \mathrm{~h}$ (b), $3 \mathrm{~h}$ (c), 6 $\mathrm{h}(\mathrm{d})$ respectively at $500 \times$ magnification

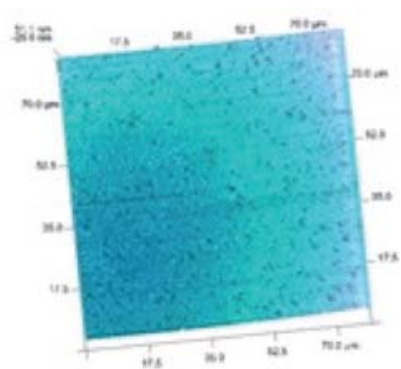

a)

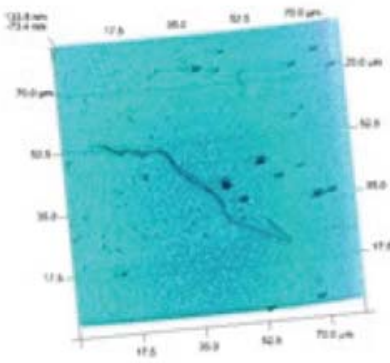

b)

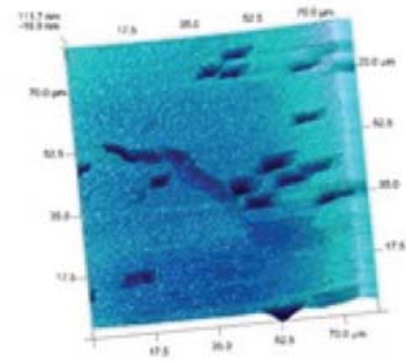

c)

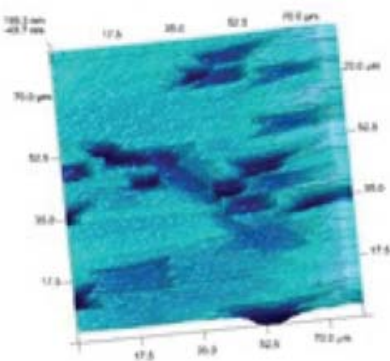

d)

Figure 8: Surface topography of the (001) face of the large crystals exposed to the dissolution media recorded at time points 0 (a), $1 \mathrm{~h}$ (b), $3 \mathrm{~h}$ (c) and $6 \mathrm{~h}(\mathrm{~d})$ respectively at $500 \times$ magnification 
The dissolution rate of the crystal face (011) is faster in comparison to (001) and is therefore more hydrophilic. The collected data confirm our previous predictions (section 3.3.) based on the internal structure and exposition of the functional groups on the individual crystal face.

These results additionally prove and explain our previous findings performed on smaller crystals isolated from the same solvent mixtures, expressing the same differences in crystal habit and the dissolution rate of the bulk (intrinsic dissolution rate), which we have at that time, explained through different hydrophillicity of the surface as determined by the drop-shape analysis on compacted disks.

\section{Conclusion}

Simvastatin crystals crystallized from different solvent mixtures showed significant differences in their shape. The crystals isolated from a more hydrophilic solvent mixture e.g. acetone/water mixture were rod-shaped whereas the crystals isolated from solvents with lower polarity, such as ethanol/heptane solvent system were plate-like.

The main difference between both samples was the size of (011) crystal face, which was larger in case of rodshaped crystals. According to the results of the dissolution kinetics performed on individual crystal faces, we can assume that this crystal face is the most polar one. Moreover, the size of the crystal face (001) in comparison to the size of the other evolved crystal faces differed between crystals expressing different crystal habit. Relatively speaking in plate-like crystals isolated from a less polar solvent mixture the crystal face (001), was significantly larger compared to the rod-shaped crystals. A slower dissolution rate from this crystal face is attributed to its lower hydrophillicity. These findings additionally prove and explain in more detail the results of our previous research performed on smaller crystals isolated from the same solvent mixtures, expressing the same differences in crystal habit and the dissolution rate.

The crystals obtained from polar solvents exhibit relatively large polar crystal faces, while nonpolar crystal faces are the most prominent in both cases. These crystal faces also vary in their mechanical properties as a consequence of more molecular voids present on the polar crystal faces. Since polar crystal faces are less expressed in plate-like crystals, the material isolated from less polar solvent mixture is more rigid. Different mechanical properties can significantly alter the biopharmaceutical properties of the final dosage form. In our case faster dissolving rod-shaped simvastatin crystals are prone to be plastically more deformed when formulated into a tablet in comparison to the plate-like crystals. They could therefore require more disintegration power in order to achieve proper disintegration of the final dosage form.
As it was already described in the literature, the polarity of the solvent and the interactions that lead to its preferential adsorption at selected crystal faces of the solute are critical factors in determining the habit of a crystallizing solid. We have shown in the case of simvastatin that grown crystal faces can vary considerably with regards to their polarity (and therefore relative hydrophobicity) depending on the atoms/functional groups that emerge at the surface of the crystal due to specific interactions with the crystallization solvent.

Hydrophilic crystals were isolated from more polar solvent mixture, whereas a less polar solvent mixture contributed to more hydrophobic crystals with slower dissolution kinetics. The dissolution kinetics is dependent on the incidence and size of specific crystal faces. Present work proves that it is also possible to alter the dissolution rate by only changing the crystal habit of the substance without changing any other physico-chemical parameters such as particle size, specific surface area and/or internal structure of the active pharmaceutical ingredient.

Habit modification is therefore one of the possible approaches by which we can regulate the dissolution rate and consequently improve the bioavailability of poorly water soluble active pharmaceutical ingredients which do not express the polymorphism phenomena.

\section{References}

1. L. Borka, J.K. Haleblian, Acta Pharm Jugosl. 1990, 40, 71- 94.

2. S. Datta, D. J. W. Grant, Nat. Rev. Drug Discov. 2004, 3, 4257. http://dx.doi.org/10.1038/nrd1280

3. A. Mersmann: Crystallization technology Handbook, CRC Press, 2001. http://dx.doi.org/10.1201/9780203908280

4. G. Murtaza, Acta Pol. Pharm. - Drug Res. 2012, 69, 581- 590.

5. Simvastatin - MeSH - NCBI, http://www.ncbi.nlm.nih.gov /mesh/68019821

6. T. Jiang, N. Han, B. Zhao, Y. Xie, S. Wang, Drug Dev. Ind. Pharm. 2012, 38, 1230-9.

http://dx.doi.org/10.3109/03639045.2011.645830

7. G. Kuminek, G. S. Rauber, M. K. Riekes, C. E. M. de Campos, G. A. Monti, A. J. Bortoluzzi, S. L. Cuffini, S. G. Cardoso, J. Pharm. Biomed. Anal. 2013, 78-79, 105-111. http://dx.doi.org/10.1016/j.jpba.2013.02.001

8. F. H. Allen, Acta Crystallogr. 2002, 58, 380-388. http://dx.doi.org/10.1107/S0108768102003890

9. M. Hušak, B. Kratochvil, A. Jegorov, J. Brus, J.Maixner, J. Rohliček, Struct Chem. 2010.

10. J. Čejka, B. Kratochvil, I. Cisarova, A. Jegorov, Acta Crystallogr. 2003, 59, 428-430. http://dx.doi.org/10.1107/S0108768103007389

11. H. G. Brittain, J. Pharm. Sci. 2002, 91, 1573-1580. http://dx.doi.org/10.1002/jps.10115

12. G. G. Z. Zhang, D. Law, E. A. Schmitt, Y. Qiu, Adv. Drug Deliv. Rev. 2004, 56, 371-390.

http://dx.doi.org/10.1016/j.addr.2003.10.009 
13. V. R. K. Prasad, R. I. Ristic, D. B. Sheen, J. N. Sherwood, Int. J. Pharm. 2002, 238, 29-41. http://dx.doi.org/10.1016/S0378-5173(02)00053-4

14. A. Nokhodchi, A.Homayouni, R. Araya, W. Kaialy, W. Obeidat, K. Asare-Addo, RSC Adv. 2015, 5, 46119-46131.

15. M. Maghsoodi, O. Taghizadeh, G. P. Martin, A. Nokhodchi, Int. J. Pharm. 2008, 351, 45-54.

http://dx.doi.org/10.1016/j.ijpharm.2007.09.033

16. A. Nokhodchi, N. Bolourtchian, R. Dinarvand, Int. J. Pharm. 2003, 250, 85-97. http://dx.doi.org/10.1016/S0378-5173(02)00488-X

17. M. Tenho, J. Aaltonen, P. Heinänen, L. Peltonen, V. P. Lehto, J. Appl. Crystallogr. 2007, 40, 857-864. http://dx.doi.org/10.1107/S0021889807034553
18. Y. Shekunov, D. J. W. Grant, R. J. Latham, J. N. Sherwood, J. Phys. Chem. B. 1997, 101, 9107-9112. http://dx.doi.org/10.1021/jp9720505

19. J. J. De Yoreo, Rev. Mineral. Geochemistry. 2003, 54, 57-93.

20. Z. Berkovitch-Yellin, J Am Chem Soc. 1985, 107, 82398253. http://dx.doi.org/10.1021/ja00312a070

21. M. Vable: Mechanics of Materials, Oxford University Press, 2002

22. S. Myerson: Handbook of Industrial Crystallization (Sec. Ed.), Elsevier, 2007.

23. M. E. Smith: Effects of crystal orientation on the dissolution behaviour of calicte by chemical and microscopic analyses, Master thesis, 2011.

\section{Povzetek}

Izboljšane in-vivo lastnosti končne farmacevtske oblike, ki vsebuje slabo topno zdravilno učinkovino, lahko dosežemo s spreminjanjem fizikalno-kemijskih lastnosti zdravilne učinkovine, ne samo v smislu prilagajanja notranje strukture, temveč tudi preko spremembe kristalnega habitusa.

Za pojasnitev tega pristopa smo, na primeru simvastatina, z mikroskopom na atomsko silo spremljali hitrost raztapljanja izoliranih večjih monokristalov, ki so imeli enako notranjo strukturo in so se razlikovali po zunanji obliki kristala.

Hitrost raztapljanja določenih kristalnih ploskev je bila bistveno hitrejša glede na ostale.

Razlika v hitrosti raztapljanja izoliranih monokristalov je bila posledica večje pojavnosti bolj polarnih kristalnih ploskev v primeru paličastih kristalov, ki smo jih izolirali iz polarnih topil, kar smo ugotovili na osnovi poglobljene raziskave morfoloških lastnosti, orientacije monokristalov in asignacije specifičnih funkcionalnih skupin za vsako izmed izraženih kristalnih ploskev. 